difference consists in the relative size of the electrodes. For example, in the case of a zinc-copper cell containing a single electrolytic fluid, the maximum cell is made with a lathode of sheet-copper folded and curved, presenting 300 times as much surface as the thin copper rod which serves as anode, whilst in the minimum cell the preportion is reversed, so that the polarisa. tion at the surface of the copper attains at once its maximum value. The value of the E.M.F. of the cells when filled with dilute sulphuric acid, and having the zinc amalgamated, was $1 \cdot 072$ volts maximum, and 0.272 volts minimuw. Many other electrolytes were examined by M. Reynier. The electromotive force was measured upon a galvanometer of high resistance.

M. REXNIER bas suggested a modification of his maximum cell to serve as a standard of electromotive force-namely, a cell having a very large copper electrode, and a very small amalgamated zinc electrode, immersed in a solution of sea-salt. According to M. Reynier, this battery has an E.M.F. of 0.82 volts, and maintains this value within I per cent. even when the circuit was loosed for two hours through a resistance of 820 ohms. M. Reynier prefers this combination to one containing sulphate of zinc in solution, because of the liability of the latter salt to contain free acid.

M. Heniz Becquerel has been pursuing his researches upon the infra-red rays of the spectrum. For the investigation of this region there are four methods, the first of them involving the use of a line-thermopile and a rock-salt prism; the second, Abney's photographic method; the third, Langley's method, with bolometer and a reflecting diffraction grating; the fourth, that of Becquerel, depending upon the discovery that the infrared rays have the effect of extinguishing the glow of a phosphorescent body exposed previously to ultra-violet rays. M. Becquerel finds that water, for example, gives in the region to which this method is applicable three well marked absorptionbands, having wave-lengths respectively of 930 , 1080, and 1230 .

THE newest result of Becquerel's researches is worth more than passing mention. He finds that there exist in this wholly invisible region of the spectrum bright-line spectra-equally invisible, of course-just as in the visible parts of the spectrum, ob-ervable in the radiations of hot vapours. Thus, incandescent sodium vapour prints upon the previously "insolated" phosphorescent substance two well-marked lines (wave-lengths 810 and rog8), corresponding to two bright lines hitherto unknown. The extent of the region which is capable of being explored by this nuvel process is from wave-length 760 to 1300 , or exceeding in extent that of the whole of the visible and ultra-violet rays.

AN interesting experiment is described in the Zeitschrift des elektrotechnischen Vereins, in Vienna, by Prof. von Waltenhofen, made by means of Noe's thermo-electric generators. If a current from a voltaic battery has been sent for a few moments through one of these generators, it is capable of yielding a discharge like a secondary battery. This effect is so far a mere repetition of a well-known experiment of Peltier, and is due to the change of temperature at the junction, called the Peltier effect. But von Waltenhofen observes that the effects are different according to the sense of the charging current. In one case, with increasing charging currents the discharge currents also increased, and were always in the opposite sense to that of the charging current. But when the charging current was reversed, it was found that with increasing charging currents the discharge currents at first increase, then attain a maximum, then decrease to zero, then actually recommence in the converse sense, namely, in the same sense as that of the charging current. Prof. von Waltenhofen is disposed to attribute this anamalous result to the lack of symmetry in the disposition of the alternate solderings of the generators, and to their alternately unequal resistance causing alternately unequal developments of heat due to resistance.

In proof of the law of proportion between the thickness of a square vibrating plate and its pitch, Dr. Elsas gives the following neat experiment. Let three plates be cut from the same sheet of material, of the same size and form. Cement two of these together so as to produce a plate of double thickness Then, on exciting the single plate and the double plate by communicating to them respectively the vibrations of two tuning forks whose pitches are as $I: 2$, the plates will be excited in identical manners, as will be seen by dusting sand upon them, the clang-figures being identical.

LORD RAYLEIGH has reprinted for private circulation in pamphlet form several of his most valuable optical papers, including those on the manufacture, reproduction by photography, and theory, of diffraction-gratings, and those on colourmixtures.

LORD RAYLEIGH has also reprinted some of his papers on electricity and on absolute pitch, from NATURE and from the Reports of the British Association, in a convenient pamphlet form.

THE question whether condensation of steam is a cause of electrification has been examined afresh by S. Kalischer in the Physical Laboratory at Berlin. According to the views of Faraday, this is a cause of electrification, and upon the alleged phenomenon Prof. Spring has founded a theory of the origin of thunderstorms. Landerer thought he had heard sounds in the telephone due to condensation of moisture on the line wires. Kalischer has in vain repeated the experiment. $\mathrm{He}$ has also examined, by means of the quadrant electrometer, whether any such electrification could be observed from the deposit of mois. ture upon the surface of a vessel containing ice or some artificial cooling mixture. The whole of the results were negative.

AMONGST the many recent suggestions for primary batteries is one due to MM. Lalande and Chaperon, in which oxide of copper is used as a depolarising agent. The oxide, in powder, is placed in or on a sheet of copper or iron. The positive element is zinc, and the exciting liquid caustic potash. A zincate of potash is formed by the solution of the zinc. The cell is absolutely inactive when the circuit is open. When closed, the current is remarkably constant. According to Hospitalier, the electromotive force is 0.98 volt. It must of course be closed from the air, to prevent absorption of carbonic acid by the potash. The reduced copper is reoxidised by simple exposure to the air.

$J_{N}$ a series of studies on the copper voltameter, published in the Repertorium der Physik by Dr. H. Hammerl, the following conclusions are formulated :- I. The material condition of the surface of the electrode, that is to say, whether it is covered with a bright copper film or not, has no influence on the amount of the deposit. 2. The changes of concentration of the copper solution, brought about in the voltameter by the current itself, cannot be sufficiently prevented by stirring. 3. Heating the fluid to boiling causes the deposit to come down almost completely in the state of cuprous oxide: it is partially oxidised even at temperatures between $40^{\circ}$ and $60^{\circ} \mathrm{C}$. 4. The greatest permissible strength of current, for which the deposit may be safely assumed to be a measure of the current, is about 7 amperes per square decimetre of the cathode surface.

\section{THE EVIDENCE FOR EVOLUTION IN THE \\ HISTORY OF THE EXTINCT MAMMALIA}

THE subject to which $\mathrm{I}$ wish to call your attention this morn ing requires neither preface nor apology, as it is one with the discussion of which you are perfectly familiar. My object in bringing it before the general session of the Association was in view of the fact that you were all familiar with it in a general way, and that it probably interests the members of sections which do not pursue the special branch to which it refers, as well as those which do; also, since it has been brought before us in various public addresses for many years during the meetings of this Association, I thought it might be well to be introduced at this meeting of this Association, in order that we might not omit to have all the sides of this interesting question presented.

The interests which are involved in it are large : they are chiefiy, however, of a mental and metaphysical character; they do not refer so much to industrial and practical interests, nor do they involve questions of applied science. They involve, however, questions of opinion, questions of belief, questions which affect human happiness, I venture to say, even more than questions of applied science; certainly, which affect the happiness of the higher grades of men and women more than food or clothing, because they relate to the states of our mind, explaining as they do the reasons of our relations to our fellow-beings and to all things by which we are surrounded, and the general system of the forces by which we are surrounded. So it has always appeared to me : hence I have selected the department of biology, and have taken a great interest in this aspect of it.

I A lecture by Prof. E. D. Cope of Philadelphia, given in genera session before the American Association for Advancement of Science at Minneapolis, August 20, 1883. Stenographically reported for Science. 
The doctrine of evolution, as taught by the biologists of today, has several stages as grounds or parts of its presentation. First, the foundation principle is this: That the species of animals and of plants, the species of organic beings, as well as the various natural divisions into which these organic being; fall, have not always been as we see them to-day, but they have been produced by a process of change which has progressed from age to age through the influence of natural laws; that, therefore, the species which now exist are the descendants of other species which have existed heretofore, by the ordinary processes of reproduction; and that all the various structures of organic beings which make them what they are, and which compel them to act as they now act, are the result of gradual or sudden modifications and changes during the periods of geologic time. That is the first phase or aspect which meets the naturalist or biol ogist.

An ther phase of the question relates to the origin itself of that life which is supposed to inhabit or possess organic beings, There is an hypothesi; of evolution which derives this life from no-life, which derives vitality from non-vitality. That is another branch of the subject, to which I cannot devote much attention to-day. There is still another department of the subject, which relates to the origin of mind, and which derives the mental organisation of the higher animals, especially of man, from preexistent types of mental organisation. This gives us a genealogy of mind, a history of the production or creation of mind, as it is now presented in its more complex aspects as a function of the human brain. This aspect of the subject is, of course, interesting, and upon that I can touch with more confidence than upon the question of the origin of Jife.

Coming now to the question of the origin of structures, we have by this time accumulated a vast number of facts which have been collated by laborious and faithful workers, in many countries and during many years; so that we can speak with a good deal of confidence on this subject also. As to the phenomena which meet the student of zoology and botany at every turin, I would merely repeat what every one knows-and I beg pardon of my biological friends for telling them a few wellknown truths, for there may be those present who are rot in the Biological Section - that the phenomena which meet the student of biology come under two leading classes : the one is the remarkable fidelity of species in reproducing their like. "Like produces like," is the old theorem, and is true in a great many cases; just as coins are struck from the die, just as castings are turned out from a common mould. It is one of the most wonderful phenomena of nature, that such complex organisms, consisting of so many parts, should be repeated from age to age, and from generation to generation, with such surprising fidelity and precision. This fact is the first that strikes the student of these sciences. The general impression of the ordinary person would be that these things must continue unchanged. When I began to study zoology and botany, I was remarkably surprised to find there was a science of which I had no conception, and that was this remarkable reproduction of types one after another in succession. After a man has had this idea thoroughly assimilated by his honest and conscientious studies, he will be again struck with another class of facts. He will find, not unfrequently, that this doctrine does not apply. He will find a series of facts which show that many individuals fail to coincide with their fellows precisely, the most remarkable variations and the most remarkable half-way attitudes and double-sided aspects occurring; and he will come to the concluiion, sooner or later, that like does not produce like with the same precision and fidelity with which he had supposed it did. So that we have these two classes of facts, - the one relating $t$, , and expressing, the law of heredity; the other, which expresses the law of metamorphosis. I should not like to say which class of facts is the most numerously presented to the student. In the present fauna we find many groups of species and varieties before us; but how many species we have, how many genera we have, and families, we cannot definitely state. Th: more precise and exact a person is in his definition and in his analysis, the more definite his science becomes, and the more precise and scientific his work. It is a case of analysis and forms. What the scales are to the chemist and the physicist, the rule and measure are to the biologist. It is a question of dimension, it is a question of length and breadth and thickness, a question of curves, a question of crooked shapes or simple shapes,-rarely simple shapes, mostly crooked, generally bilateral. It require; that one should have a mechanical eye, and should have also sonething of an artistic eye to appreciate these forms, to measure them, a nd to be able to compare and weigh them.

Now, when we come to arrange our shapes and our measurements, we find, as I said before, a certain number of identities, and a certain number of variations. This question of variation is so common and so remarkabln, that it becomes ferfectly evident to the specialist in each department that like does not at all times produce like. It is perfectly clear, ard I will venture the assertion that nearly all the binlogists in this room will bear me witness, that variability is practically unlimited in its range, unlimited in the number of its examples, unlimited in t'e degree to which it extends. That is to say, the species vary by failing to retain certain characteristics, and generic and other characters are found to be absent or present in accordance with some law to be discussed further on.

I believe that this is the simplest mode of stating and explain. ing the law of variation: that some forms acquire something which their parents do not po:sess; and that those which acquire something additional have to pass through more numerous stages than those which have not acquired so much had themselves passed through.

Of course we are met with the opposite side of the case,- this law of heredity. We are told that the facts there are not accounted for in that way; that we cannot pass from one class of facts to the other class of facts; what we find in one class is not applicable to the other. Here is a question of rational pro. cesses, of ordinary reason. If the rules of chemistry are true in America, I imagine they are true in Australia and Africa, altkough I have not been there to see. If the law of gravitation is effective here, I do not need to go to Australia or New Zealand to ascertain whether it is true there. So, if we find in a group of animals a law sufficient to account for their creation, it is not necessary to know that others of their relatives have gone through a similar process. I am willing to allow the ordinary practical law of induction, the practical law of inference, to carry me over these gaps, over these interruptions. And I state the case in that way, because this is just where some people differ from me, and that is just where I say the simple question of rationality comes in. I cannot believe that nature's law's are so dissimilar, so irregular, so inexact, that those which u e can see and understand in one place are not true in another and that the question of geological likelihocd is similar to the question of geographical likelihood. If a given process is true in one of the geological periods it is true in another; if it is true in one part of the world it is true in another; because $I$ find interruptions in the series here, it does not follow that there need be interruptions clear through from age to age. The assumption is on the side of that man who asserts that transitions have not taken place between forms which are now distinct.

We are told that we find no sort of evidence of that transition in past geological periods; we are assured that stc'l changes have not taken place; we are even assured that no such sign of such transition from one species to another has ever been observed, - a most as:onishing assertion to make to a biologist, or $b y$ a biologist; and such persons bave eren the temerity to cite special cases, as between the wolf ard the dog. Many of our domestic dogs are nothing but wolves, which have been modified by the hand of man to a very slight extent indeed. Many dogs, in fact nearly all dogs, are descendants of wild species of various countries, and are but slightly modified.

To take the question of the definition of species. Supposing we have several species well defined, say four or five. In the process of investigation we obtain a larger number of individual, many of which hetray characters which invalidate the definitions. It becomes necessary to unite the four or five species into one. And so then, because our system requires that we shall have accurate definitions (the whole basis of the system is definitionsyou know the very comprehension of the subject requires definitions), we throw them all together, because we cannot define all the various special forms as we did before, until we have but one species. And the critic of the view of evolution tells us, "I told you so! There is but one species, after all. There is no such thing as connection between sfecies; you never will find it." Now, how many discoveries of this kind will be neces-ary to convince the world that there are connections between species? How long are we to go on finding connecting link =, and putting them together, as we have to do for the sake of the definition, and then be told that we have nevertheless no intermediate forms between species? The matter is too plain for further comment. We throw them together simply because our 
definitions requice it. If we knew all the known individuals which have lived, we should have no species, we should have no genera. That is all there is of it, It is simply a question of a universal accretion of material and the collection of information. I do not believe that the well-defined groups will be found to run together, as we call it, in any one geological period, certainly in no one recent period. We recognise, however, that they diverge to a wonderful extent ; cne group has diverged at one period, and another one has become diversified in a different period; and so each one has its history, some beginning farther back than others, some reaching far back beyond the very begirning of the time when fossils could be preserved. I call attention to this view because it is a very easy matter for us to use words for the purpose of confusing the mind; for, next to the power of language to express clear ideas, is its power of expressing no ideas at all. As we all know, we can say wany things which we cannot think. It is a very easy thing to say twice two is equal to six, but it is impossible to think it.

I would cite what I mean by variations of species in one of its phases : I would just mention a genus of snakes, Ophibolus, which is found in the United States. If we take the species of this snake genus as found in the Northern States, we have a good many species well defined. If we go to the Gulf States and examine our material, we see we have certain other species well defined, and they are very nicely defined and distinguished. If now we go to the Pacific coast, to Arizona and New Mexico, we shall find another set of species well defined indeed. If we take all these different types of our specimens of different localities together, our species, as the Germans say, all tumble together; definitions disappear, and we have to recognise, out of the preliminary list of thirteen or fourteen, only four or five. That is simply a case of the kind of fact with which every biologist is perfectly familiar.

When we come to the history of the extinct forms of life, it is perfectly true then that we cannot observe the process of descent in actual operation, because, forsooth, fossils are necessarily dead. We cannot perceive any activities because fossils have ceased to act. But if this doctrine be true we should get the series, if there be such a thing; and we do, as a matter of fact, find longer or shorter series of structures, series of organisms proceeding from one thing into another form, which are exactly as they ought to be, if this process of development by descent had taken place.

I am careful to say this, because it is literally true, as we all must admit, that the system must fall into some kind of order or other. You could not collect bottles, you could not collect old shoes, but you could make some kind of a serial order of them. There are no doubt characters, by which such and such shoes could be distinguished from other shoes, these bottles from other bottles; but it is also true that we have, in recent forms of life in zoology and botany, irrefragable proofs of the metamorphoses, and transformations, and changes of the species, in accordance with the doctrine which we commenced with.

We now come to the second chapter of our subject. With the assumption, as I take it, already satisfactorily proven, of species having changed over into others-in considering this matter of geological succession or biological succession, I bring you face to face with the nature and mode of the change, and hence we may get a glance, perhaps, at its laws.

I have on the board a sketch or table which represents the changes which took place in certain of the mammalia. I give you a summary of the kind of thing wbich we fi. $d$ in one of the branches of palæontology. I have here two figures, one representing a restoration, and the other an actual picture, of two extinct species that belong to the early Eocene period. One represents the ancestor of the horse line, Hyracotherium, which has four toes on his anterior feet, and three behind; and the other, a type of animal, Phenacodus, which antedated all the horse series, the elephant series, the hog, the rhinoceros, and all of the other series of hoofed animals. Each presents us with the primitive position in which they first come to our knowledge in the history of geological time.

I have also arranged here a series of some leading forms of the three principal epochs of the Mesozoic times, and six of the leading ones of the Tertiary time. I have added some dates to show you the time when the faunz which are entombed in those beds were discovered in the course of our studies; and you will easily see how unsafe it is to say that any given type of life has never existed, and assert that such and such a form is unknown; and it is :till more unsafe, I think, to assert that any given form of life properly defined, or that a specific intermediate form of life, will not be found. I think it is much safer to assert that such and such intermediate forms will be found. I have frequently had the pleasure of realising anticipations of this kind. I have asserted that certain types would be found, and they have been found. You will see that I attend to the matter of time closely, because there have been a great many things discovered in the last ten or fifteen years in this department. In these forms I give the date of the discovery of the fauna in which they are embraced.

\begin{tabular}{|c|c|c|c|c|c|}
\hline 响 & 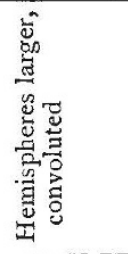 & 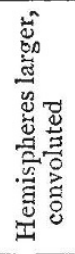 & 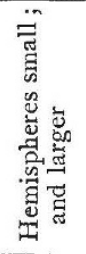 & 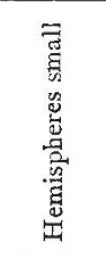 & 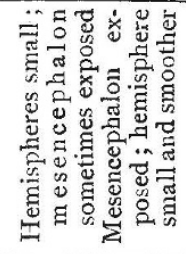 \\
\hline 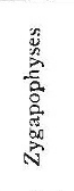 & 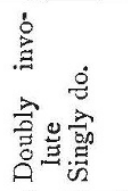 & 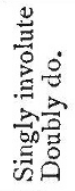 & 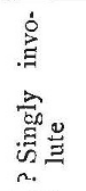 & 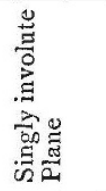 & 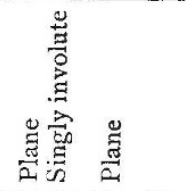 \\
\hline 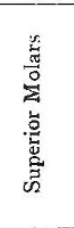 & 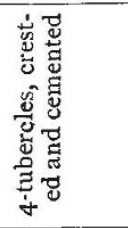 & 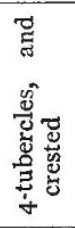 & 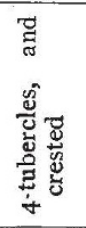 & 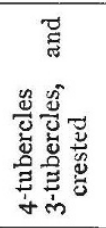 & 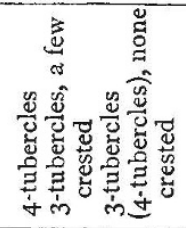 \\
\hline 宫总 & 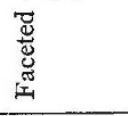 & 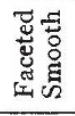 & 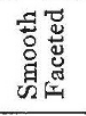 & 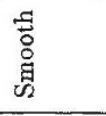 & 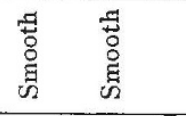 \\
\hline 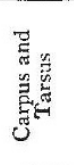 & 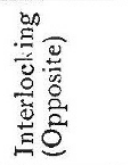 & 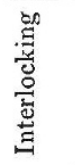 & 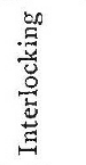 & 总 & 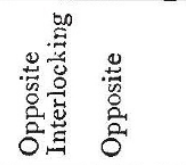 \\
\hline 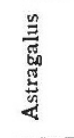 & 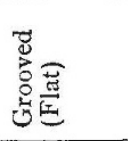 & 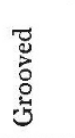 & 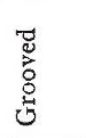 & 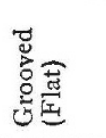 & 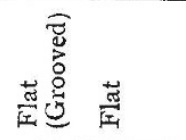 \\
\hline$\underset{\Xi}{\Phi}$ & 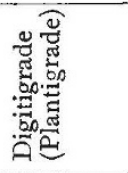 & 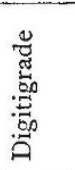 & 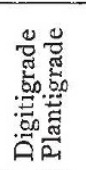 & 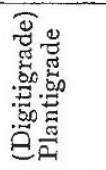 & 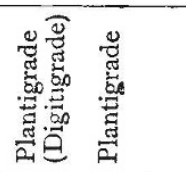 \\
\hline 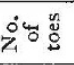 & \multicolumn{5}{|c|}{ 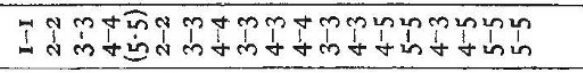 } \\
\hline 总 & 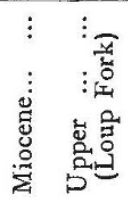 & 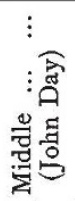 & 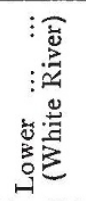 & 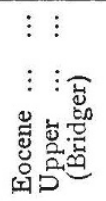 & 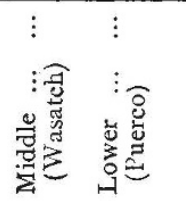 \\
\hline
\end{tabular}

Here we have the White River fauna discovered in $185^{6}$; then we skip a considerable period of time, and the next one was in I 869, when the Cretaceous series was found. Six or seven Cre. taceous faunæ have been found. Thus we have the Bridger fauna in 1870 , the Wasatch fauna in 1874 . Next we have, in 1877, the Equus beds and the fauna which they embrace, which also was found in 1878 . The Permian fauna, which is one of the last, is 1879; and the last, the Puerco, which gives the oldest and ancestral types of the modern forms of mammalia, was only found in $188 \mathrm{r}$. When I first commenced the study of this subject, about 1860 , there were perhaps 250 species known. 
There are now something near 2000 , and we are augmenting them all the time. I have found many myself : if they were distributed through the days of the year I think in some years I should have had several every day. But the accessions to knowledge which are constantly being made make it unsafe to indulge in any prophecies that, because such and such things have not been found, therefore such and such things cannot be; for we find such and such things really have been and really are discovered.

The successive changes that we have in the mammalia have taken place in the feet, teeth, and brain, and the vertebral column. The parts which present us the greatest numbers of variations are those in which many parts are concerned, as in the limbs and feet. In the Lower Eocene (Puerco) the toes were 5-5. In the Loup Fork fauna some possess toes but $\mathrm{i}-\mathbf{1}$. Prior to this period no such reduction was known, though in the Loup Fork fauna, a very few species were $5-5$. Through this entire series we have transitions steady and constant, from 5-5, to $4-5$, to $4-4$, to $4-3$, to $3-3$, to $2-2$, to $I-I$. In the Puerco period there was not a single mammal of any kind which had a good ankle-joint, which had an ankle-joint constructed as ankle-joints ought to be, with tongue and groove. The model ankle-joint is a tongue-and-groove arrangement. In this period they were all perfectly flat. As time passes on, we get them more and more grooved, until in the Loup Fork fauna and the White River fauna they are all grooved. In the sole of the foot, in the Puerco fauna, they are all flat; but in the Loup Fork fauna the sole of the foot is in the air, and the toes only are applied to the ground, with the exception of the line of monkeys, in which the feet have not become erect on the toes, and the elephant, in which the feet are nearly flat also, and the line of bears, where they are also flat. As regards the ungulation between the small bones of the palm and of the sole there is not a single instance in which the bones of the toes are locked in the Lower Eocene, as they are in the later and latest Tertiary.

When we come to the limbs, the species of the Puerco fauna have short legs. They have gradually lengthened out, and in the late periods they are nearly all relatively long.

\section{(To be continued.)}

\section{SOCIETIES AND ACADEMIES LONDON}

Royal Society, Dec. 13, 1883.- "On the Figure of Equilibrium of a Planet of Heterogeneous Density," by G. H. Darwin, F.R.S., Plumian Professor of Astronomy in the University of Cambridge.

If a rotating planet be formed of compressible fluid, the strata of equal pressure are of equal density, and the ellipticity of the strata increases from the centre outwards. Since it is supposed that the earth consolidated into its present form from a fluid or semi-fluid condition, the determination of the arrangement of internal density and of the law of ellipticity in such a planet is often called the problem of the figure of the earth. When the law of compressibility of the fluid is known, the laws of density and ellipticity are determinate, but the differential equations involved are of such complexity that only one solution of the problem is well known, viz, that associated with the names of Legendre and Laplace.'

In this solution the modulus of compressibility varies as the square of the density, but the assumption of this law appears to have been dictated more by the neces ity of solving a certain aifferential equation than by physical considerations.

The comparison of the solution of th: problcm with the observed facts with regard to the corth $\mathrm{m}$ ay he mide in several ways. The constant which determines the rate of the earth's precessional motion gives us information with regard to the arrangement of density in the interior, and the ellipticity of the surface is determined by geodesy and by the amount of a certain i nequality in the moon's motion. Now, in order that the solution of the problem of the earth's figure may be satisfactory, the same arrangement of internal density must give the observed amounts both to the precessional constant and to the ellipticity of the surface.

Laplace's solution is highly satisfactory in this respect ; and at the same time it makes the mean density of the whole earth about

$x$ The late M. Roche seems to have also solved the problem in 1848 , and his paper is fublished in the Memoirs of the Academy of Montpellier. twice as great as the density of the surface stratum. The density of rock is about $2 \cdot 8$, and that of the whole earth is about $5^{\circ} 6$.

In this state of our knowledge another solution of this cele. brated problem possesses some interest, even if its results are not quite so satisfactory as those of Laplace's theory.

In the present paper such a solution is offered. The law of compressibility of the fluid is such, that the modulus varies as a power of the density, which power may range from negative infinity to $\frac{4}{3}$. When the power is zero, we have constant com. pressibility; and when the power is unity, we have the same law of compressibility as in a gas.

The solution is expressible in a far simpler algebraic form than that of Laplace, and it differs from his solution in placing a far larger proportion of the mass of the planet in the central regions.

It is remarkable that this solution affords for the case of the earth a correspondence between the precessional constant and the surface ellipticity equally good with that of Laplace. To obtain this correspondence we have to assume the compressibility of the fluid to be nearly constant.

The density of the surface layer appears however to be 3.7 , and this is considerably greater than that of ordinary rocks. This result tells adversely to the acceptability of the proposed solution, but the discrepancy is not so serious as might appear at first sight. It appears from pendulum experiments on the Himalayan plateau and on the Andes, that there is a considerable deficiency of density underneath those great ranges. This would favour the view that our continents are a mere intumescence of the surface layers. In this case there must be a somewhat abrupt change in the law of density at only a few miles below the surface. The theory of the earth's figure can take no account of a sudden change of density on passing into a swollen superficial layer, and the value of the surface density to be used is that which is to be found immediately below the swollen part.

The author therefore points out that whilst the solution now offered cannot be held to be quite as satisfactory as that of Laplace, yet its inferiority is not of a kind to render altogether unacceptable the contention that it may be somewhere near the truth.

Linnean Society, December 20, I883.-Alfred W. Bennett. M.A., in the chair,-Messrs. N. Cantley, W. Dobson, F. G. Smart, and Rev. R. Thom were elected Fellows of the Society -Mr. S. O. Ridley exhibited and made remarks on a series of 177 vertical sections of sponges collected in the neighbourhood of Point de Galle, Ceylon, by Dr. W. C. Ondaatje, F.L.S., and transmitted to England by him in letters. They are in most instances sufficient for the identification of the genera and some species.-Mr. F. Maule Campbell showed the web of a spider (Tegenaria guyonii) which had been spun in the centre of a pasteboard cylinder, the peculiarity being the manner in which the solid part of the web was medially swung, whereas in this species of spider it is more usually on the sides of objects. - A paper was read by Mr. F. O. Bower on the structure of the stem of Rhynchopetalum montanum. The plant is a native of Abyssinia, growing in districts 11,000 to 13,000 feet above the level of the sea. It differs from its ally Lobelias in being perennial. Internally it is succulent when young, but afterwards the surface becomes scarred as the leaves drop off, and exteriorly is hardened by a thick corky deposit. Rhynchopetalum, the author shows in detail, has certain peculiarities in the arrangement of the tissue of its leaf bundles, since the cortical system does not con sist of branches of bundles of the leaf trace, but are cauline bundles, in this respect differing widely from such forms as Lathyrus casuarina, many Begonias, \&c. Rhynchopetalum, moreover, has the cortical bundles running obliquely, and forming a regular four-sided meshed network related to the leaf bases and bundles of leaf trace. In these respects it approaches Cycas, in which latter the bundles of the acces. sory cortical system are not so regular and are almost vertically arranged. Some Cycads and Rhynchopetalum also agree in the exterior appearance of their stem, so that palæontologists might be deceived in their judgment if two well-preserved specimens were examined by them. - A communication was read on the auditory ossicles of Rhytina stelleri by Alban Doran. This was based on skeletons obtained by the Vega expedition, and shown at the late International Fisheries Exhibition by the Swedish Government. The author arrives at the conclu- 